\title{
Nitrogen-doped bcc-Cr films: Combining ceramic hardness with metallic toughness and conductivity
}

Grzegorz Greczynski, Jun Lu, Olof Tengstrand, Ivan Petrov, Joseph E Greene and Lars Hultman

\section{Linköping University Post Print}

\section{Tweet}

N.B.: When citing this work, cite the original article.

Original Publication:

Grzegorz Greczynski, Jun Lu, Olof Tengstrand, Ivan Petrov, Joseph E Greene and Lars Hultman, Nitrogen-doped bcc-Cr films: Combining ceramic hardness with metallic toughness and conductivity, 2016, Scripta Materialia, (122), , 40-44.

http://dx.doi.org/10.1016/j.scriptamat.2016.05.011

Copyright: Elsevier

http://www.elsevier.com/

Postprint available at: Linköping University Electronic Press

http://urn.kb.se/resolve?urn=urn:nbn:se:liu:diva-129248

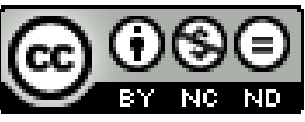





\title{
Nitrogen-doped bcc-Cr films: combining ceramic hardness with metallic toughness and conductivity
}

\author{
G. Greczynski, ${ }^{1}$ J. Lu, ${ }^{1}$ O. Tengstrand, ${ }^{1}$ I. Petrov, ${ }^{1,2}$ J.E. Greene, ${ }^{1,2}$ and L. Hultman ${ }^{1}$ \\ ${ }^{1}$ Department of Physics (IFM), Linköping University, SE-581 83 Linköping, Sweden \\ ${ }^{2}$ Materials Science and Physics Departments and the Frederick Seitz Materials Research \\ Laboratory, University of Illinois, Urbana, Illinois 61801
}

\begin{abstract}
We report the first results on nanostructured N-doped bcc-Cr films exhibiting the unique combination of ceramic hardness with metallic toughness and electrical conductivity at unexpectedly low $\mathrm{N}$ concentrations, $\sim 5$ at\%. The Cr: $\mathrm{N}$ films are deposited at $200{ }^{\circ} \mathrm{C}$ in $\mathrm{N}_{2} / \mathrm{Ar}$ mixtures by high-power pulsed magnetron sputtering using tunable time-domain control of $\mathrm{Cr}^{+}$ and $\mathrm{Cr}^{2+}$ ion fluxes incident at the film growth surface. Subplanted $\mathrm{N}$ atoms impede annealing of metal-ion induced point defects and hinder bcc-Cr grain growth, resulting in a material with a nearly isotropic nanostructure and atomically smooth surface, rather than typical Cr: $\mathrm{N}$ solid solutions consisting of faceted microcolumns.
\end{abstract}

corresponding author: grzgr@ifm.liu.se; phone: +4613281213

Keywords: CrN, thin films, toughness, resistivity, magnetron sputtering, HIPIMS, transition-metal nitrides, ion mass spectrometry 
Transition-metal nitrides (TMN) such as CrN, fabricated primarily by sputter-deposition, represent a major research field in materials science ${ }^{1,2,3,4,5,6}$ with more than 2000 publications in the past year alone. ${ }^{7}$ TMN are refractory ceramics which exhibit high hardness $H$ and elastic modulus $E$ compared to the parent metal. Small concentrations of N, in the doping regime, added to the metal typically result in the formation of solid solutions (ss) with a limited increase in hardness. For the Cr-N system during vapor deposition at temperatures typically $20-40 \%$ of the melting point of $\mathrm{CrN}\left(T_{m}=2043 \mathrm{~K}\right)$, continuously increasing the $\mathrm{N}$ content gives rise to the following sequence of phases -- bcc-Cr $\rightarrow$ bcc-Cr: $\mathrm{N}(\mathrm{ss}) \rightarrow$ hexagonal $\beta-\mathrm{Cr}_{2} \mathrm{~N} \rightarrow \mathrm{B} 1-\mathrm{NaCl}-\mathrm{CrN}$. Several papers ${ }^{8,9,10}$ report a gradual increase in hardness $H$ from $b c c-\mathrm{Cr}$ to $\beta$ - $\mathrm{Cr}_{2} \mathrm{~N}$ by a factor of 2.5 to 3. For example, Rebholz et al., observed a $1.5 \times$ increase in $H$ for ss $\mathrm{CrN}_{0.07}$ compared to pure $\mathrm{Cr}$, with both films deposited by reactive dc magnetron sputtering (DCMS) at $200{ }^{\circ} \mathrm{C}$; the authors found that all $\mathrm{CrN}_{x}$ films $(0 \leq x \leq 0.5)$ had columnar microstructures with rough surfaces characterized by $\mu$ m-size faceting.

Here, we obtain nanostructured $b c c-\mathrm{CrN}_{x}$ films, with $0.04 \leq x \leq 0.06$, which have atomically-smooth surfaces using high-power pulsed magnetron sputtering (HIPIMS) ${ }^{11,12}$ with synchronized metal-ion, rather than gas-ion, irradiation, a technique previously developed by our group. ${ }^{13}$ Surprisingly, the films have the characteristics of both metals (bcc-Cr crystal structure, electrical resistivity, and toughness) and ceramics (high hardness, 3× larger than $\mathrm{Cr}$ ).

HIPIMS is a particularly attractive technique for the growth of TMN layers due to the time separation between metal- and gas-ion fluxes incident at the substrate. ${ }^{14}$ Figure 1(a) shows energydistribution functions for $\mathrm{Cr}^{+}, \mathrm{Cr}^{2+}, \mathrm{Ar}^{+}$, and $\mathrm{N}_{2}{ }^{+}$ions at the substrate position during a reactive HIPIMS discharge pulse at a Cr target in a mixed $\mathrm{N}_{2}$ /Ar atmosphere. The total metal-ion intensity $\left(2.28 \times 10^{8} \mathrm{cps}\right)$ exceeds that of the gas ions $\left(1.63 \times 10^{8} \mathrm{cps}\right)$. In addition, average metal-ion energies 
are significantly higher as evident from the high-energy $\mathrm{Cr}^{+} / \mathrm{Cr}^{2+}$ tails which extent beyond $50 \mathrm{eV}$. The time-resolved ion fluxes at the substrate, from $t \sim 70$ to $120 \mu$ s into the pulse, are dominated by $\mathrm{Cr}^{+}$and $\mathrm{Cr}^{2+}$ (Figure 1(b)), which together account for $82 \%$ of the total ion flux over this interval. Thus, by synchronizing the substrate bias pulse $V_{s}$ to the $50-\mu$ s-long metal-ion-rich portion of the HIPIMS pulse we select predominantly metal ions arriving at the growth surface. Throughout the rest of the pulse, gas ions arrive at the substrate with the floating potential, ${ }^{15} V_{f}=$ $-10 \mathrm{~V}$, which is below the lattice-atom displacement threshold. This is in contrast to conventional DCMS, in which $V_{s}$ is constant and predominantly accelerates gas ions, with metals ions only in the few-percent range. The mean energy of ions incident at the growing film is $E_{i}=E_{i}^{0}+$ $n e\left(V_{s}-V_{p l}\right)$ [ref.16], in which $E_{i}^{0}$ denotes the average energy of ions entering the anode sheath (a few eV), $n$ accounts for the charge state of the ion, and $V_{p l}$ is the plasma potential $(\sim 10 \mathrm{~V})$. Based upon measured $E_{i}^{0}$ values and the applied bias, $V_{s}=150 \mathrm{~V}$, used in the present experiments, we estimate $E_{\mathrm{Cr}^{+}}=160 \mathrm{eV}$ and $E_{C r^{2+}}=335 \mathrm{eV}$.

Employing metal-ion irradiation provides a unique kinetic pathway for controlling film growth. ${ }^{17,18}$ Accelerated metal ions are incorporated as film constituents; thus, bombardmentinduced residual lattice damage is reduced, resulting in lowered film stress as compared to conventional sputter deposition with rare-gas ion bombardment. ${ }^{19,20}$

Plan-view transition electron microscopy (TEM), cross-sectional TEM (XTEM), and scanning electron microscopy (XSEM) images in Figure 2 compare the micro- and nanostructures of bcc-Cr layers grown in pure $\operatorname{Ar}$ (Figs. 2(a)-(c)) with those grown in 2\% $\mathrm{N}_{2} / \mathrm{Ar}$ mixtures (Figs. 2(d)-(f)). All films are $2.0 \pm 0.1 \mu \mathrm{m}$ thick, deposited on $\mathrm{Si}(001)$ substrates under essentially the same $\mathrm{Cr}^{+} / \mathrm{Cr}^{2+}$ metal-ion irradiation conditions. ${ }^{21} \mathrm{Cr}$ layers grown in pure $\mathrm{Ar}$ and with synchronous bias during metal-mode HIPIMS exhibit columnar microstructures, with no open boundaries, and an 
average column diameter $\langle d\rangle$ near the top surface of $1400 \pm 200 \AA$. The 011, 002, and 112 bcc diffraction rings in selected-area electron diffraction (SAED) patterns (inserts in Figs. 2(b) and 2(c)), are composed of individual spots indicating large grain sizes compared to the size of the SAED aperture (2500 $\AA$ diameter). The $x$-ray diffraction (XRD) peaks are typical for polycrystalline films as illustrated in the inset in Figure 2 (b), showing the 110 peak of the $b c c-C r$ with relatively narrow FWHM of $0.4^{\circ}$. The average $b c c-\mathrm{Cr}$ grain size in the growth direction estimated from XRD peak broadening using Williamson-Hall (WH) analysis ${ }^{22}$ is $3100 \pm 700 \AA$, the film stresses are -1.7 GPa, and the root-mean-square surface roughness determined by atomic force microscopy is $48 \AA$.

A dramatically different nanostructure (see Figs. 2(d)-(f)) results from the addition of a small amount of nitrogen (2 mol\%) to the Ar discharge with otherwise identical film growth conditions. In contrast to previously reported ss-Cr: $\mathrm{N}$ microcolumnar growth, ${ }^{8,9,10}$ the layers are composed of bcc-Cr nanograins with no microcolumns. The $\mathrm{N}$ content of these films, measured using time-of-flight elastic recoil detection analysis (ToF-ERDA) employing a $36 \mathrm{MeV}^{127} \mathrm{I}^{8+}$ probe beam incident at $67.5^{\circ}$ with recoils detected at $45^{\circ}$, is only $4.9 \pm 1.0$ at $\%(x=0.049 \pm 0.01)$. Film densities, determined by $x$-ray reflectivity, increase from $6.78 \mathrm{~g} / \mathrm{cm}^{3}$ for $\mathrm{Cr}$ layers (94\% of the bulk density) to $7.16 \mathrm{~g} / \mathrm{cm}^{3}$ (99.4\% of bulk density) for $\mathrm{CrN}_{0.05}$ films. The SAED patterns obtained from both cross-sectional and plan-view samples (insets in Figs. 2(e)-(f)) exhibit bcc diffraction rings with uniform angular intensity, indicating a significant decrease in grain size, compared to HIPIMS Cr layers. This is consistent with $\mathrm{CrN}_{0.05} \mathrm{XRD} \theta-2 \theta$ scans displaying extensive $b c c$ diffraction-peak broadening: the 110 bcc-Cr peak, shown in the inset of Figure 2(e), has a FWHM of $1.7^{\circ}$. The diffraction peak also exhibits a shoulder extending to $\sim 40^{\circ}$, the interval containing the 002 and 111 reflections of hexagonal $\mathrm{Cr}_{2} \mathrm{~N}$ peak. The average grain size of $\mathrm{CrN}_{0.05}$ 
layers, obtained from WH analysis, is $120 \pm 40 \AA$. Plan view and XTEM images show grains elongated in growth direction which are a few nm wide and 10-20 nanometer high. The films have a compressive stress of $2.3 \mathrm{GPa}$ and a surface roughness of $2.6 \AA$.

For $\mathrm{CrN}_{x}$ layers with $0.1<x<0.3$, grown with approximately the same $\mathrm{Cr}^{+} / \mathrm{Cr}^{2+}$ irradiation at $V_{s}=150 \mathrm{~V}, \mathrm{XRD}$ reveals the presence of hexagonal $\beta-\mathrm{Cr}_{2} \mathrm{~N}$ crystallites within the $b c c-\mathrm{CrN}_{x}$ matrix. Electron microscopy shows that films within this compositional range remain nanocrystalline and smooth. At even higher $\mathrm{N}_{2}$ supply, the $b c c-\mathrm{CrN}_{x}$ phase disappears, columnar growth is restored, and the films are composed of stoichiometric compounds (initially $\beta-\mathrm{Cr}_{2} \mathrm{~N}$ and then NaCl-structure cubic CrN, both of which have wide single-phase fields ${ }^{23}$ ).

X-ray photoelectron spectroscopy (XPS) results (Figs. 1(c)-(d)) from bcc- $\mathrm{CrN}_{0.05}$ films ion-etched with $0.5 \mathrm{keV} \mathrm{Ar}{ }^{+}$ions incident at $70^{\circ}$ with respect to the surface normal, reveal that the position and the shape of $\mathrm{N}$ 1s XPS peaks (normalized to the highest intensity feature) are identical to those acquired from $\beta$ - $\mathrm{Cr}_{2} \mathrm{~N}$ reference samples, with both sets of peaks being distinctly different from those of $\mathrm{CrN}$ due to the difference in $\mathrm{Cr}-\mathrm{N}$ bond energies. The $\mathrm{Cr} 2 \mathrm{p}$ spectrum from $\mathrm{CrN}_{0.05}$ is also identical to that of bcc-Cr. This is expected, however, because of the dilute $\mathrm{N}$ concentration. Energy-dispersive $\mathrm{x}$-ray mapping of plan-view and XTEM samples (not shown) reveals no evidence of $\mathrm{N}$ grain boundary segregation. In addition, the surface roughness decreases from $48 \AA$ for metallic $\mathrm{Cr}$ to $2.6 \AA$ for $\mathrm{CrN}_{0.05}$. Thus, $\mathrm{CrN}_{0.05}$ is essentially atomically flat, which is remarkable for 2- $\mu$ m-thick polycrystalline layers.

The dramatic change in the $\mathrm{CrN}_{x}$ film nanostructure upon incorporation of only 5 at\% $\mathrm{N}$ also results in an unexpected combination of film properties. Figure 3 shows that $H$ increases nearly three-fold, from 9.5 GPa for metallic $\mathrm{Cr}$ films to $26.3 \mathrm{GPa}$ for $\mathrm{CrN}_{0.05}$. The latter value is essentially equal to that of stoichiometric $\mathrm{Cr}_{2} \mathrm{~N}$ and $\mathrm{CrN}^{24}$ Simultaneously, the low $\mathrm{N}$ 
concentration and retained $b c c$ crystal structure result in $\mathrm{CrN}_{0.05}$ having a low electrical resistivity, $\rho=54 \mu \Omega-\mathrm{cm}, \sim 50 \times$ less than that of $\mathrm{CrN}$. Hexagonal-structure $\mathrm{Cr}_{2} \mathrm{~N}$ films have resistivities ranging from 210 to $1800 \mu \Omega-\mathrm{cm}$ as a function of the $\mathrm{N} / \mathrm{Cr}$ ratio, and an increased surface roughness, while $H$ remains unchanged. Atomically-flat films with isotropic nanograins are obtained in the $\mathrm{N}$ concentration range from 4 to 26 at $\%$.

The toughnesses of $\mathrm{Cr}, \mathrm{CrN}_{0.05}$, and $\mathrm{CrN}$ films are evaluated via nanoindentation experiments performed with a sharp cube-corner diamond tip, which produces higher stress in the area of contact, on a series of 3000 - $\AA$-thick $\mathrm{CrN}_{\mathrm{x}}$ films grown on $\mathrm{MgO}(001)$ substrates. All indents are $7000 \AA$ deep, extending $4000 \AA$ into the MgO. Typical SEM images of the indents are shown in Figure 4. While CrN reference samples (Fig. 4(c)) exhibit severe cracking, characteristic of brittle ceramics, cracks are not observed in Cr (Fig.4(a)), which instead exhibit material pile-up along indent edges, typical of plastic flow in ductile materials. Similarly, no cracks are present in the $\mathrm{CrN}_{0.05}$ indents (Fig. 4(b)). This, together with the hardness data, indicates that the nanocrystalline $\mathrm{CrN}_{0.05}$ films combine the ductility of metallic films with the hardness of ceramic layers.

In order to explain the formation of hard, yet tough, $b c c-\operatorname{CrN}_{x}(0.04 \leq x \leq 0.26)$ nanocrystalline films in a growth parameter space not previously accessed, the differences in nanostructure evolution between conventional DCMS deposition and film growth with synchronized-bias HIPIMS metal-ion bombardment have to be considered. For DCMS deposition of pure $\mathrm{Cr}$ at room temperature (RT) to several hundred ${ }^{\circ} \mathrm{C}$, surface diffusion is active and results in competitive V-shape columnar growth with local epitaxy on individual columns which develop faceted, rough surfaces. ${ }^{7}$ Introducing a small fraction of $\mathrm{N}_{2}$ in the DCMS discharge results in the incorporation of randomly-dispersed $\mathrm{N}$ in the bcc-Cr matrix giving rise, in turn, to a limited degree 
of solid-solution hardening. ${ }^{10}$ When bias is applied during DCMS deposition, the growing film surface is exposed to gas ion bombardment which leads to Ar incorporation in interstitial sites resulting in compressive stress ${ }^{25,26}$ of several GPa, while HIPIMS-deposited CrN with constant DC bias exhibits significantly higher stresses of 8-9 GPa. ${ }^{27}$

In the HIPIMS experiments described here, we apply substrate bias only during the metalrich phase of the HIPIMS pulses. Thus, ion assistance during film growth is controlled by $\mathrm{Cr}$ ions which are incorporated into lattice sites. TRIM (Transport of Ions in Matter) simulations performed with a Monte Carlo program included in the SRIM (Stopping power and Range of Ions in Matter) software package indicate that energetic $\mathrm{Cr}^{+} / \mathrm{Cr}^{2+}$ bombardment $\left(160 \leq E_{i} \leq 335 \mathrm{eV}\right.$ with $V_{s}=150 \mathrm{~V}$ ) initiates strongly-overlapping collision cascades with an average projected $\mathrm{Cr}$ range $\xi_{c r} \simeq 14 \AA$, corresponding to several bcc-Cr lattice spacings. This causes continuous intermixing in the near-surface region due to effective momentum transfer resulting from the near perfect mass match between the incident ions and the film atoms.

For Cr HIPIMS layers, surface atom mobilities are relatively high resulting in wide $b c c$ columns, i.e., the columnar structure is essentially the same as for DCMS Cr films. However, small additions of $\mathrm{N}_{2}$ during HIPIMS with metal-ion-synchronized bias dramatically change the pathway for incorporating $\mathrm{N}$, which occurs primarily via recoil implantation, leading to the formation of a unique nanostructure. The presence of $\mathrm{N}$ atoms impedes the recovery of radiationinduced point defects and promotes the formation of dispersed $\mathrm{Cr}_{2} \mathrm{~N}$ nanocrystallites encapsulated in a $b c c-\mathrm{CrN}_{\mathrm{x}}$ matrix. A small shoulder on the $110 \mathrm{bcc}$-Cr peak at the position of the most intense $111 \mathrm{XRD}$ reflection of hexagonal $\mathrm{Cr}_{2} \mathrm{~N}$ is an indication of the onset of the formation of $\mathrm{Cr}_{2} \mathrm{~N}$ nanograins. We carried out HRTEM and lattice-resolution STEM imaging in an aberrationcorrected Titan instrument with point resolution $0.7 \AA$ in an attempt to image interstitial $\mathrm{N}$ within 
bcc-grains. Because of the small atomic number of $\mathrm{N}$, it was not resolved even by this state-ofthe-art instrument. However, TEM and XTEM images show that all $\mathrm{CrN}_{0.05}$ grains have significant local strain contrast manifested as speckles in both dark- and bright-field imaging, which can only be explained by interstitial $\mathrm{N}$; pure metal Cr grains would not support interstitial Cr. The presence of interstitial $\mathrm{N}$ is further supported by the XPS $\mathrm{N}$ 1s signature from $\mathrm{CrN}_{0.05}$ layers, Fig. 1(d), which is identical to that from $\mathrm{Cr}_{2} \mathrm{~N}$ films. We propose that the speckles are due to $\mathrm{Cr}_{2} \mathrm{~N}$ nanocrystallites formed by small dispersed small $\mathrm{N}$ islands, located between 110 planes in bcc-Cr, creating local strain fields. The $b c c-\mathrm{CrN}_{\mathrm{x}}$ matrix is densely packed, as evident from XRR results showing film densities approaching bulk values. The surprisingly high hardness of $b c c-\mathrm{CrN}_{0.05}$, $26 \mathrm{GPa}, \sim 3 \times$ that of pure $\mathrm{Cr}$ films, is primarily due to reduced grain boundary sliding and lower dislocation densities per grain, the Hall-Petch effect, ${ }^{28,29}$ while the $\mathrm{CrN}_{0.05}$ resistivity remains metallic.

In summary, the film synthesis technique described here combines metal-ion-irradiation with the incorporation of small amounts, $\sim 5$ at $\%$, of reactive gas to achieve continuous formation of dispersed $\mathrm{Cr}_{2} \mathrm{~N}$ nanocrystallites within isotropic $b c c-\mathrm{CrN}_{0.05}$ nanograins. Resulting layers possess atomically-smooth surfaces and exhibit properties characteristics of both metals (bcc-Cr crystal structure, electrical resistivity, and toughness) and ceramics (high hardness). The discovery of this unique nanostructure points the way toward a new generation of transition-metal-based multifunctional thin films for diverse applications ranging from diffusion barriers to low-friction, wear-, and corrosion-resistant coatings.

\section{Acknowledgements}


Financial support from the Swedish Research Council VR Grants 2013-4018 and 2014-5790, VINN Excellence Center Functional Nanoscale Materials (FunMat) Grant \#2005-02666, the Knut and Alice Wallenberg Foundation Grant \#2011.0143 and the Swedish Government Strategic Faculty Grant In Materials Science to Linköping University (Grant SFO Mat-LiU AFM) are gratefully acknowledged. We thank Dr. Jens Jensen and Dr. Jeremy Schroeder for help with ToF-E ERDA and resistivity measurements. 


\section{Figure Captions}

Fig. 1 (a) Ion energy distribution functions (IEDFs) recorded at the substrate position during sputtering of a Cr target operated in HIPIMS modes in mixed $\mathrm{Ar} / \mathrm{N}_{2}$ discharges at a total pressure of 3 mTorr. The IEDFs correspond to the highest target current density 20 - $\mu$ s portion of the $100-\mu \mathrm{s}$ HIPIMS pulses. (b) Time evolution of the energy-integrated flux of $\mathrm{Cr}^{+}, \mathrm{Cr}^{2+}, \mathrm{Ar}^{+}, \mathrm{N}_{2}{ }^{+}$, and $\mathrm{N}^{+}$ ions incident at the substrate. (c) Cr 2p and (d) N 1s XPS core-level spectra obtained from Cr, $\mathrm{CrN}_{0.05}, \mathrm{Cr}_{2} \mathrm{~N}$, and $\mathrm{CrN}$ layers grown by synchronized-bias, $V_{s}=150 \mathrm{~V}$, HIPIMS in pure Ar as well as $\mathrm{Ar} / \mathrm{N}_{2}$ mixtures on $\mathrm{Si}(001)$ substrates at $200{ }^{\circ} \mathrm{C}$.

Fig. 2 (a) XSEM, (b) XTEM, and (c) plan-view TEM images obtained from bcc-Cr layers grown by synchronized-bias, $V_{s}=150 \mathrm{~V}$, HIPIMS in pure Ar. SAED patterns corresponding to XTEM and TEM images together with $\theta-2 \theta$ XRD scans are shown as inserts. (d)-(f) Corresponding images for $\mathrm{CrN}_{0.05}$ films grown with $2 \% \mathrm{~N}_{2} / \mathrm{Ar}$ mixtures under essentially the same $\mathrm{Cr}^{+} / \mathrm{Cr}^{2+}$ metalion irradiation conditions. The total pressure in all experiments is 3 mTorr.

Fig. 3 Resistivity $\rho$, hardness $H$, and RMS surface roughness $w$ of 2 - $\mu$ m-thick $\operatorname{CrN}_{x}$ films as a function of $\mathrm{N}$ concentration $x$. Layers are grown by synchronized-bias, $V_{s}=150 \mathrm{~V}$, HIPIMS in $\mathrm{Ar} / \mathrm{N}_{2}$ mixtures on $\mathrm{Si}(001)$ substrates at $200^{\circ} \mathrm{C}$. The total pressure in all experiments is 3 mTorr, while the $\mathrm{N}_{2}$ partial pressure varies from 0 to 2 mTorr.

Fig. 4 SEM images of 7000- $\AA$-deep nanoindents in a 3000- $\AA$-thick (a) Cr, (b) $\mathrm{CrN}_{0.05}$, and (c) $\mathrm{CrN}$ films grown by synchronized-bias, $V_{s}=150 \mathrm{~V}$, HIPIMS in $\mathrm{Ar} / \mathrm{N}_{2}$ mixtures on $\mathrm{MgO}(001)$ 
substrates at $200{ }^{\circ} \mathrm{C}$. The indents, extending $4000 \AA$ into the MgO substrate, were made using a sharp cube-corner diamond tip.

\section{References}

${ }^{1}$ D.M. Mattox, G.J. Kominiak, J. Vac. Sci. Technol. 9 (1972) 528

${ }^{2}$ L. Hultman, J.-E. Sundgren, J.E. Greene, D.B. Bergstrom, and I. Petrov, J. Appl. Phys. 78 (1995) 5395

${ }^{3}$ M. Stefenelli, R. Daniel, W. Ecker, D. Kiener, J. Todt, A. Zeilinger, C. Mitterer, M. Burghammer, J. Keckes, Acta Mater. 85 (2015) 24

${ }^{4}$ I. Petrov, P.B. Barna, L. Hultman, and J.E. Greene, J. Vac. Sci. Technol. A 21 (2003) S117

${ }^{5}$ R. Meshkian, A.S. Ingason, M. Dahlqvist, A. Petruhins, U.B. Arnalds, F. Magnus, J. Lu, J. Rosen, Physica Status Solidi - Rapid Research Letters 9 (2015) 197

${ }^{6}$ K. Yalamanchili, I.C. Schramm, E. Jiménez-Piqué, L. Rogström, F. Mücklich, M. Odén, N. Ghafoor, Acta Mater. 89 (2015) 22

${ }^{7}$ http://apps.webofknowledge.com/; accessed on 2016-02-22

${ }^{8}$ T. Hurkmans, D.B. Lewis, J.S. Brooks, W.-D. Munz, Surf. Coat. Technol. 86-87 (1996) 192

${ }^{9}$ P. Hones, R. Sanjines, F. Levy, Surf. Coat. Technol. $94-95$ (1997) 398

${ }^{10}$ C. Rebholz, H. Ziegele, A. Leyland, A. Matthews, Surf. Coat. Technol. 115 (1999) 222

${ }^{11}$ V. Kouznetsov, K. Macak, J. M. Schneider, U. Helmersson and I. Petrov, Surf. Coat. Technol. 122 (1999) 290

${ }^{12}$ For review on HIPIMS see: U. Helmersson, M. Lattemann, J. Bohlmark, A. P. Ehiasarian and J. T. Gudmundsson, Thin Solid Films 513 (2006) 1; K. Sarakinos, J. Alami, S. Konstantinidis, Surf. Coat. Technol. 204 (2010) 16611684

${ }^{13}$ G. Greczynski, J. Lu, M. Johansson, J. Jensen, I. Petrov, J.E. Greene, and L. Hultman, Surf. Coat. Technol. 206 (2012) 4202

${ }^{14}$ K. Macak, V. Kouznetsov, J. Schneider, U. Helmersson and I.Petrov, J. Vac. Sci. Technol. A 18 (2000) 1533

${ }^{15}$ G. Greczynski, J. Lu, J. Jensen, I. Petrov, J.E. Greene, S. Bolz, W. Kölker, Ch. Schiffers, O. Lemmer and L. Hultman, Thin Solid Films 556 (2014) 87

${ }^{16}$ J. E. Greene, J.-E. Sundgren, L. Hultman, I. Petrov, and D. B. Bergstrom, Appl. Phys. Lett. 67 (1995) 2928

${ }^{17}$ G. Greczynski, J. Jensen, L. Hultman, Thin Solid Films 519 (2011) 6354

${ }^{18}$ G. Greczynski, J. Lu, J. Jensen, S. Bolz, W. Kölker, Ch. Schiffers, O. Lemmer, J.E. Greene, and L. Hultman, Surf. Coat. Technol. 257 (2014) 15

${ }^{19}$ I. Petrov, L. Hultman, J.-E, Sundgren, J.E. Greene, J. Vac. Sci. Technol. A 10 (1992) 265

${ }^{20}$ G. Greczynski, J. Lu, J. Jensen, I. Petrov, J.E. Greene, S. Bolz, W. Kölker, Ch. Schiffers, O. Lemmer and L. Hultman, J. Vac. Sci. Technol. A 30 (2012) 061504

${ }^{21} \mathrm{Cr}^{+} / \mathrm{Cr}^{2+}$ metal-ion fluxes do not change significantly with small changes in the $\mathrm{N}_{2} / \mathrm{Ar}$ partial-pressure ratio since the ionization potentials of $\mathrm{N}(14.50 \mathrm{eV}), \mathrm{N}_{2}(15.55 \mathrm{eV})$ and $\mathrm{Ar}(15.75 \mathrm{eV})$ are similar, all being lower than the $\mathrm{Cr}$ second ionization potential $(16.54 \mathrm{eV})$. Thus, no dramatic change in the electron distribution function is expected upon replacing $\mathrm{Ar}$ with small amounts of $\mathrm{N}_{2}$ in the gas mixture, implying that the $\mathrm{Cr}^{2+}$ population is not significantly affected.

${ }^{22}$ The Williamson-Hall analysis technique for estimating the crystalline grain size along the growth direction, based upon XRD peak broadening, is explained in, for example, Chapter 3 in M. Birkholz, "Thin Film Analysis by X-ray Scattering”, ISBN-10: 3-527-31052-5, Wiley-VCH, Weinheim (2006).

${ }^{23}$ P. Yashar, X. Chu, S. A. Barnett, J. Rechner, Y. Y. Wang, M. S. Wong, W. D. Sproul, Appl. Phys. Lett. 72 (1998) 9987

${ }^{24}$ P.H. Mayrhofer, Ch. Mitterer, L. Hultman, H. Clemens, Prog. Mater. Sci. 51 (2006) 1032-1114

${ }^{25}$ A.G. Blachman, Metall. Trans. 2 (1971) 699

${ }^{26}$ J.A. Thornton, J. Tabock, D.W. Hoffman, Thin Solid Films 64 (1979) 111

${ }^{27}$ G. Sáfrán, C. Reinhard, A.P. Ehiasarian, P.B. Barna, L. Székely, O. Geszti, P.E. Hovsepian, J. Vac. Sci. Technol. A 27 (2009) 174

${ }^{28}$ E.O. Hall, Proc. Phys. Soc. London B, 64 (1951) 747

${ }^{29}$ N.J. Petch, J. Iron Steel Inst. 174 (1653) 25 

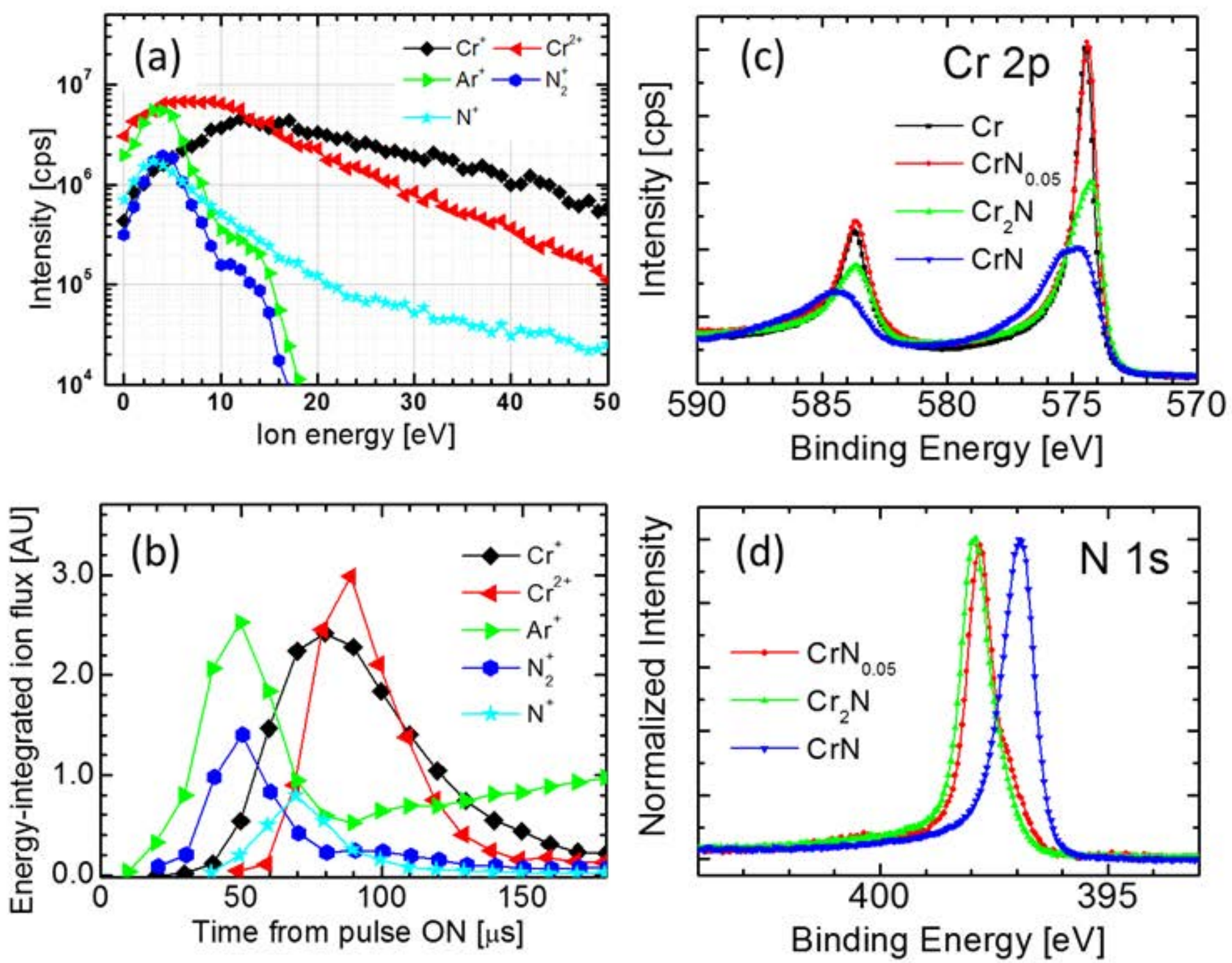

Fig. 1 (a) lon energy distribution functions (IEDFs) recorded at the substrate position during sputtering of a Cr target operated in HIPIMS modes in mixed $\mathrm{Ar} / \mathrm{N}_{2}$ discharges at a total pressure of $3 \mathrm{mTorr}$. The IEDFs correspond to the highest target current density 20 - $\mu$ s portion of the 100- $\mu$ s HIPIMS pulses. (b) Time evolution of the energy-integrated flux of $\mathrm{Cr}^{+}, \mathrm{Cr}^{2+}, \mathrm{Ar}^{+}, \mathrm{N}_{2}{ }^{+}$, and $\mathrm{N}^{+}$ions incident at the substrate. (c) $\mathrm{Cr} 2 \mathrm{p}$ and (d) N 1s XPS core-level spectra obtained from $\mathrm{Cr}, \mathrm{CrN}_{0.05}, \mathrm{Cr}_{2} \mathrm{~N}$, and $\mathrm{CrN}$ layers grown by synchronized-bias, $\mathrm{V}_{\mathrm{s}}=150 \mathrm{~V}$, HIPIMS in pure $\mathrm{Ar}$ as well as $\mathrm{Ar} / \mathrm{N}_{2}$ mixtures on $\mathrm{Si}(001)$ substrates at $200^{\circ} \mathrm{C}$. 


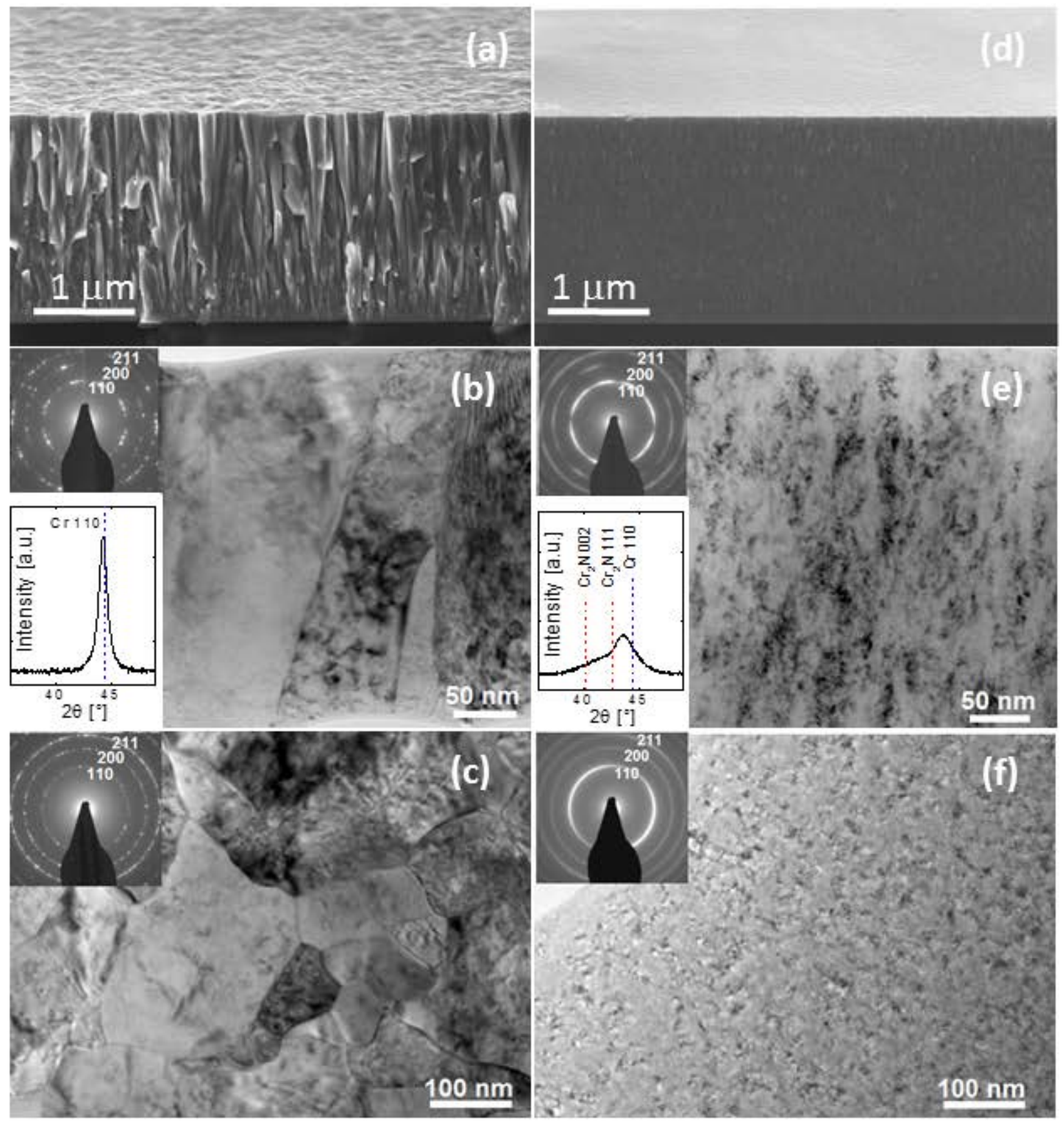

Fig. 2 (a) XSEM, (b) XTEM, and (c) plan-view TEM images obtained from bcc-Cr layers grown by synchronized-bias, $V_{s}=150 \mathrm{~V}$, HIPIMS in pure Ar. SAED patterns corresponding to XTEM and TEM images together with $\theta-2 \theta$ XRD scans are shown as inserts. (d)-(f) Corresponding images for $\mathrm{CrN}_{0.05}$ films grown with $2 \% \mathrm{~N}_{2} / \mathrm{Ar}$ mixtures under essentially the same $\mathrm{Cr}^{+} / \mathrm{Cr}^{2+}$ metal-ion irradiation conditions. The total pressure in all experiments is 3 mTorr. 

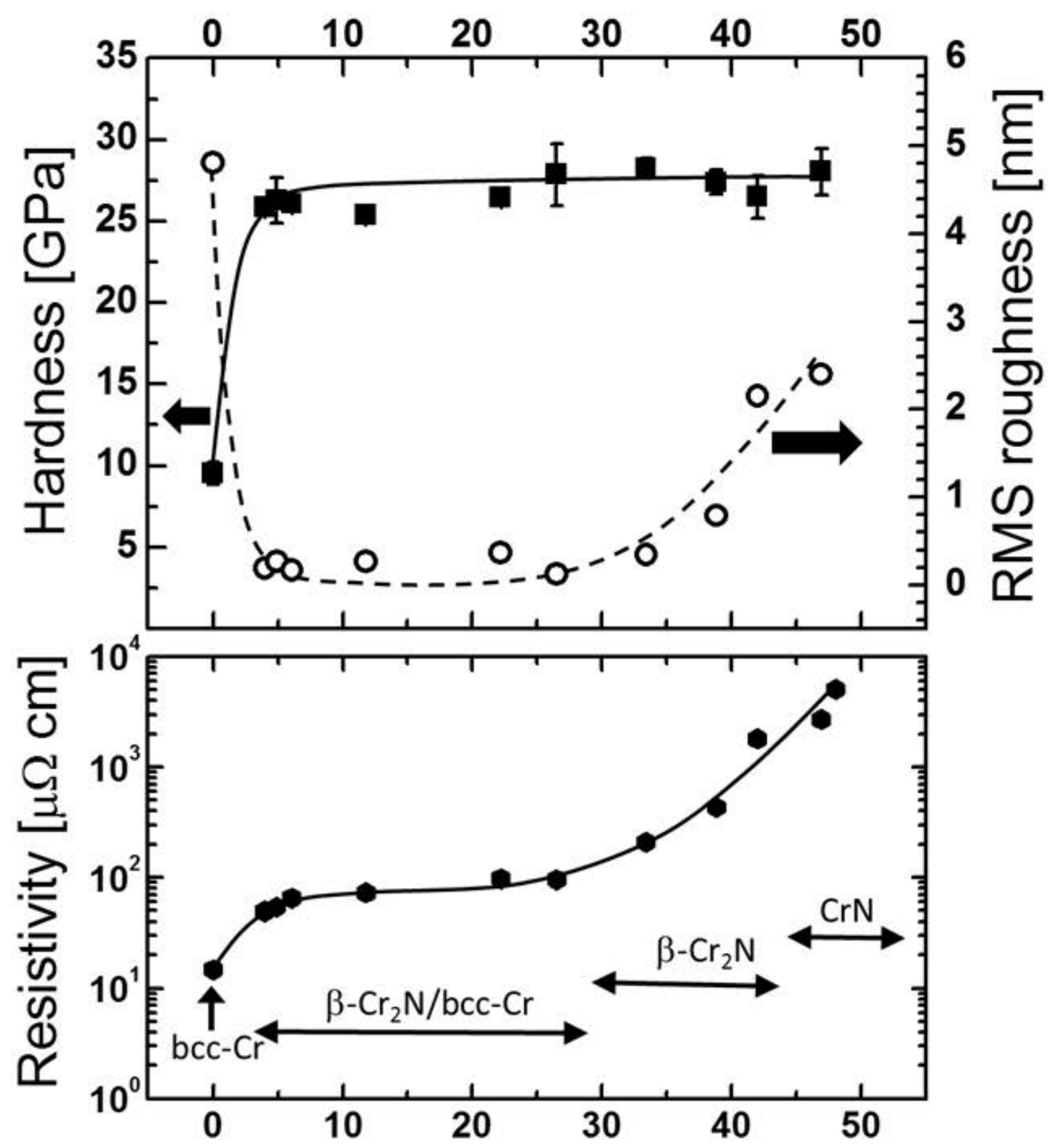

Nitrogen conc. [at\%]

Fig. 3 Resistivity $\rho$, hardness $H$, and RMS surface roughness $w$ of $2-\mu \mathrm{m}$ thick $\mathrm{CrN}_{x}$ films as a function of $\mathrm{N}$ concentration $x$. Layers are grown by synchronized-bias, $V_{s}=150 \mathrm{~V}$, HIPIMS in $\mathrm{Ar} / \mathrm{N}_{2}$ mixtures on $\mathrm{Si}(001)$ substrates at $200{ }^{\circ} \mathrm{C}$. The total pressure in all experiments is $3 \mathrm{mTorr}$, while the $\mathrm{N}_{2}$ partial pressure varies from 0 to $2 \mathrm{mTorr}$. 

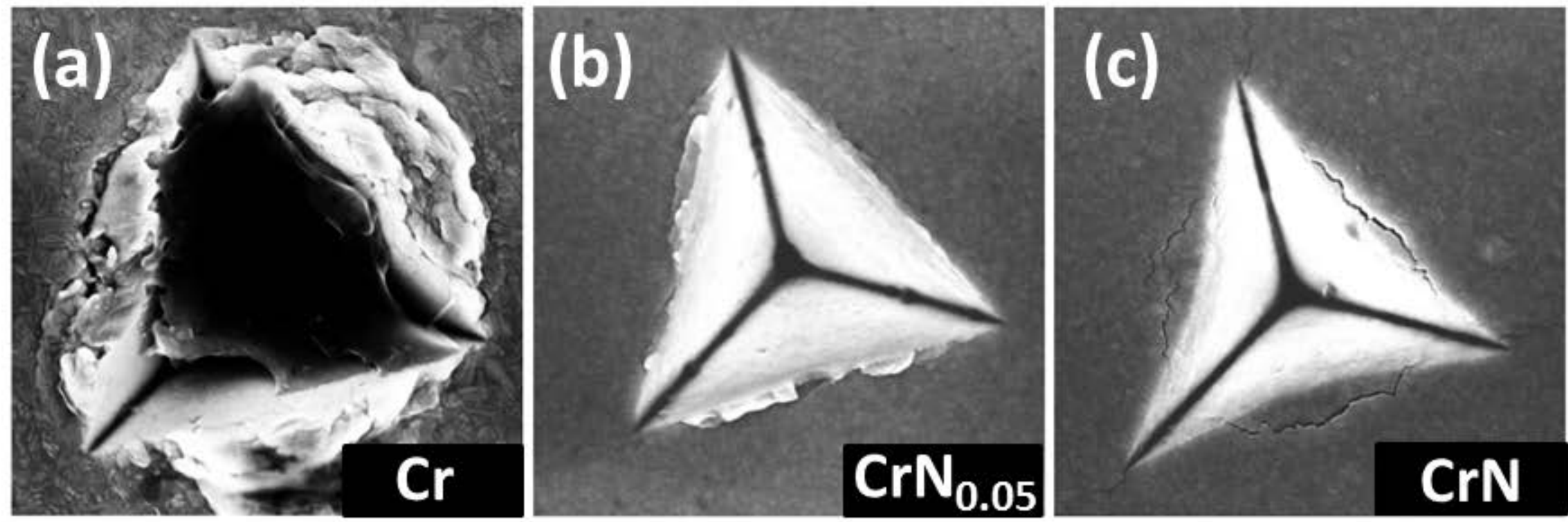

Fig. 4 SEM images of 7000- $\AA$-deep nanoindents in a $3000-\AA$-thick (a) $\mathrm{Cr}$, (b) $\mathrm{CrN}_{0.05}$, and (c) $\mathrm{CrN}$ films grown by synchronized-bias, $V_{s}=150 \mathrm{~V}$, HIPIMS in $\mathrm{Ar} / \mathrm{N}_{2}$ mixtures on $\mathrm{MgO}(001)$ substrates at $200{ }^{\circ} \mathrm{C}$. The indents, extending $4000 \AA$ into the $\mathrm{MgO}$ substrate, were made using a sharp cube-corner diamond tip. 